\title{
Autoxidation of a 4-iminoimidazolidin-2-one with a tertiary 5-hydrogen to its 5-hydroxy derivative
}

\author{
Violina T. Angelova, ${ }^{a}$ Nikolay G. Vassilev, ${ }^{b}$ Anne-Sophie Chauvin, ${ }^{c}$ Asen H. Koedjikov, \\ Petko M. Ivanov, ${ }^{b}$ and Ivan G. Pojarlieff ${ }^{b^{*}}$ \\ ${ }^{a}$ Faculty of Pharmacy, Medical University, ul. Dunav 2 , Sofia Bulgaria \\ ${ }^{b}$ Institute of Organic Chemistry, Bulgarian Academy of Sciences, ul. Acad. G. Bonchev block 9, \\ Sofia 1113, Bulgaria \\ ${ }^{c}$ Ecole Polytechnique Fédérale de Lausanne, Laboratoire de Chimie Supramoléculaire des \\ Lanthanides, BCH 1405, CH-1015 Lausanne, Switzerland \\ E-mail: ipojarli@orgchm.bas.bg
}

\begin{abstract}
Chemoselective autoxidation of 4-imino-1,5-dimethyl-3-(4-nitrophenyl)imidazolidin-2-one (1b) to its 5-hydroxy derivative 2 occurred in solutions of DMSO- $d_{6}$, acetonitrile- $d_{3}$ or refluxing ethanol. Also bis(imidazolidin-5-yl) peroxide $\mathbf{5}$ was isolated as a minor product. It crystallizes as a 1:1 mixture of $R^{*}, R^{*}$ and $R^{*}, S^{*}$ diastereomers, whereas the NMR spectra of the reaction solution in DMSO- $d_{6}$ showed unequal amounts of the two isomers. Molecular mechanics modeling studies with the MM3 force field indicate the $R^{*}, S^{*}$ diastereomer as the more stable one. The 5-unsubstituted and the 5,5-dimethyl substituted imines 1a and 1c, respectively, were found stable against autoxidation; the difference in reactivity of $\mathbf{1 b}$ is attributed to the single 5methyl group enhancing the population of the enamine tautomer. The 5-hydroxy-4-imino-1,5dimethylimidazolidin-2-one (2) underwent acid hydrolysis to form 5-hydroxyhydantoin 4.
\end{abstract}

Keywords: Autoxidation, 4-iminoimidazolidin-2-one, 5-hydroxy-4-imino-5-methylimidazolidin -2-one, 5-hydroxy-5-methylimidazolidine-2,4-dione

\section{Introduction}

Apart from causing aging and deterioration of products, autoxidation can be a useful synthetic method because of its simplicity and economy in reactants using molecular oxygen in air. ${ }^{1,2}$ Autoxidation can complicate the synthesis of imines or their enamine tautomers, particularly that of imines of simple aldehydes. ${ }^{3}$ Recently, ${ }^{4}$ we prepared 4-imino-3-(4-nitrophenyl)imidazolidin2-ones 1 (Scheme 1). Contrary to the 5-unsubstituted derivative 1a and the 5,5-dimethyl substituted derivative 1c, the 5-methyl derivative $\mathbf{1 b}$ was found to be unstable turning yellow in 
the solid state or upon heating in solution, and a satisfactory elemental analysis could not be obtained.
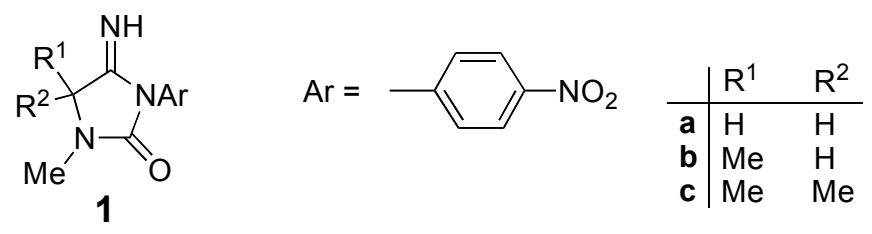

\section{Scheme 1}

We now report that the instability of 4-imino-1,5-dimethyl-3-(4-nitrophenyl)imidazolidin-2one (1b) is caused by its autoxidation, which was found to occur in solution by selectively forming the 5-hydroxy derivative 2 (Scheme 2).

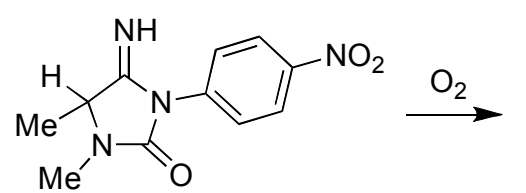

$1 b$<smiles>CN1C(=O)N(c2ccc([N+](=O)[O-])cc2)C(=N)C1(C)O</smiles>

2

\section{Scheme 2}

4-Iminoimidazolidin-2-ones are ready precursors to hydantoins, which have an extremely wide range of biological activity. ${ }^{5}$ In view of the versatile chemical transformations of a hydroxyl group, an easily obtainable 5-hydroxyhydantoin should be of considerable synthetic interest.

\section{Results}

Preparation of pure 1b. 4-Iminoimidazolidin-2-ones 1 were obtained ${ }^{4}$ from cyclization of the respective cyanoalkylureas 3 (Scheme 3 ).

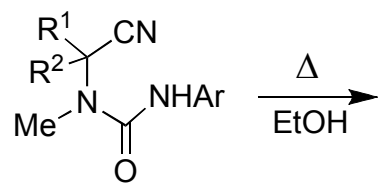

3a-c<smiles>[R]C1([R])C(=N)[NH+]([AlH2])C(=O)N1C</smiles>

$1 a-c$

\section{Scheme 3}


While cyanoalkylureas $\mathbf{3 a}$ and $3 \mathbf{c}$ (with two $\alpha$-hydrogens and two $\alpha$-methyl groups, respectively) in refluxing ethanol for 1 hour ${ }^{4}$ smoothly cyclized to the corresponding imines $\mathbf{1 a}$ and $\mathbf{1 c}$, the imine $\mathbf{1 b}$ with one methyl group in position 5 could not be isolated in a pure state due to its instability. When the cyclization of $\mathbf{3 b}$ was carried out by refluxing for only 15 min in dry ethanol, a pure (NMR) product $\mathbf{1 b}$ was obtained.

Monitoring the autoxidation of $1 \mathbf{b}$ by ${ }^{1} \mathbf{H}$ NMR. The course of autoxidation of $\mathbf{1 b}$ in DMSO- $d_{6}$ is clearly illustrated by the ${ }^{1} \mathrm{H}$ NMR scans with time (Figure 1). The methyl doublet displayed by $\mathbf{1 b}$ at $\delta 1.44$ converts with time into a singlet at $\delta 1.54$ assigned to the methyl group of 2 . The weak signals around $\delta 1.6$ can be attributed to methyl resonances of side products, two of which coincide with methyl resonances of peroxide 5 (vide infra; see Table 2). The total integral of these minor signals amounts to approximately $10 \%$, that of 2 to about $90 \%$ of the total yield. The same course of the reaction was observed in acetonitrile- $d_{3}$. The transformation of the methyl derivative $1 \mathbf{b}$ was considerably retarded when argon was bubbled into the NMR tube for $10 \mathrm{~min}$ before it was stoppered. On the other hand, the reaction rate was substantially increased when air was bubbled into the tube periodically.

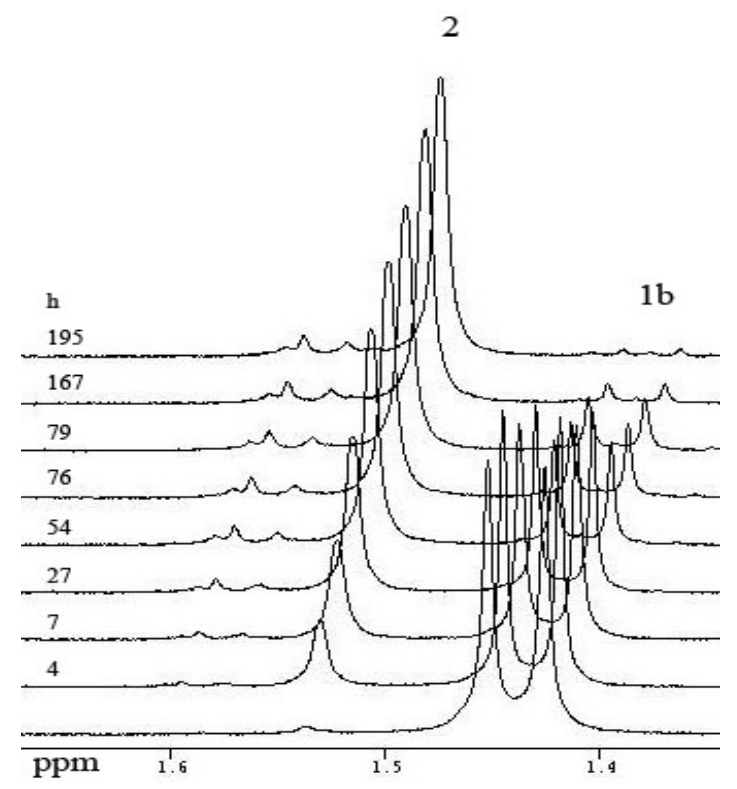

Figure 1. ${ }^{1} \mathrm{H}$ NMR scans of the 5-methyl region in DMSO- $d_{6}$ over 8 days (h elapsed from start) at $300 \mathrm{~K}$ showing the conversion of $\mathbf{1 b}$ (doublet at $\delta 1.44$ ) into 2 (singlet at $\delta 1.54$ ).

Identification of autoxidation products. Identification of the $\alpha$-hydroxy imine $\mathbf{2}$ is based on its high resolution ESI-tof mass spectrum with the molecular peak equaling $\left[\left(\mathrm{M}_{\mathbf{1 b}}+16\right)+1\right]^{+}$. The 
presence of a hydroxyl group is indicated by IR bands for free and hydrogen-bonded OH groups at 3660 and $3350 \mathrm{~cm}^{-1}$, respectively (Table 1).

Table 1. Characteristic IR wavenumbers $\left[\mathrm{cm}^{-1}\right]$

\begin{tabular}{lllllll}
\hline Compound & Phase & $\mathrm{C}=\mathrm{O}$ & $\mathrm{C}=\mathrm{N}$ & $\mathrm{NH}$ & $\mathrm{OH}$ & $\mathrm{O}-\mathrm{O}$ \\
\hline $\mathbf{1 b}$ & $\mathrm{KBr}$ & $1737 \mathrm{~m}$ & $1665 \mathrm{~s}$ & 3281 & & \\
$\mathbf{2}$ & $\mathrm{CHCl}_{3}$ & $1757 \mathrm{~m}$ & 1668 & 3312 & $3660 ; 3350$ broad & \\
$\mathbf{5}$ & $\mathrm{KBr}$ & 1751 & 1680 & 3282 & & 850 \\
\hline
\end{tabular}

The position of the 5-hydroxyl group in $\mathbf{2}$ was indicated by the transformation of the doublet of 5-methyl in $\mathbf{1 b}$ at $\delta 1.44$ into a singlet at $\delta 1.54$ in the NMR spectrum (Figure 1, Table 2); this is in agreement with the replacement of $5-\mathrm{H}$ in $\mathbf{1 b}$ by the 5-OH group in $\mathbf{2}$. The 5-methyl group in 2 shows a long range coupling with the neighboring $\mathrm{OH}$; this interaction was confirmed by a COSY experiment. Hydrolysis of $\mathbf{2}$ in aqueous $\mathrm{HCl}$ afforded the hydantoin 4 (Scheme 4).

Table 2. NMR spectra (DMSO- $\left.d_{6}\right)$ : Chemical shifts $\delta$ [ppm] from TMS, $J[\mathrm{~Hz}]$

\begin{tabular}{|c|c|c|c|c|c|c|c|c|c|c|}
\hline${ }^{1} \mathrm{H}$ & $\mathrm{C}-\mathrm{CH}_{3}$ & \multicolumn{2}{|c|}{$\mathrm{N}-\mathrm{CH}_{3}$} & $\mathrm{CH}$ & \multicolumn{3}{|c|}{ 2',6'- and 3',5'-H (AA'BB') } & \multicolumn{2}{|c|}{$\mathrm{C}=\mathrm{N}-\mathrm{H}$} & $\mathrm{OH}$ \\
\hline $1 b^{a}$ & $\begin{array}{l}1.44 \mathrm{~d} \\
J=6.7\end{array}$ & \multicolumn{2}{|c|}{$2.86 \mathrm{~s}$} & $\begin{array}{c}4.21 \mathrm{dq} \\
J=1.4 \\
6.7\end{array}$ & \multicolumn{3}{|c|}{$\begin{array}{c}\delta_{\mathrm{AA}}{ }^{\prime}=7.84, \delta_{\mathrm{BB}}{ }^{\prime}=8.29 \\
J_{\mathrm{AB}}=8.9, J_{\mathrm{BB}}=2.5 \\
J_{\mathrm{AB}}=0.4, J_{\mathrm{AA}}=2.6\end{array}$} & \multicolumn{2}{|c|}{$\begin{array}{l}8.65 \mathrm{~d} \\
\mathrm{~J}=1.4\end{array}$} & - \\
\hline 2 & $1.54 \mathrm{~s}$ & \multicolumn{2}{|c|}{$2.83 \mathrm{~s}$} & - & \multicolumn{3}{|c|}{$\begin{array}{c}\delta_{\mathrm{AA}^{\prime}}=7.85, \delta_{\mathrm{BB}^{\prime}}=8.31 \\
J_{\mathrm{AB}}=9.1, J_{\mathrm{BB}^{\prime}}=2.7 \\
J_{\mathrm{AB}^{\prime}}=0.3, J_{\mathrm{AA}^{\prime}}=2.7\end{array}$} & \multicolumn{2}{|c|}{$8.93 \mathrm{~s}$} & $6.70 \mathrm{~s}$ \\
\hline 4 & $1.50 \mathrm{~s}$ & \multicolumn{2}{|c|}{$2.83 \mathrm{~s}$} & - & \multicolumn{3}{|c|}{$\begin{array}{c}\delta_{\mathrm{AA}^{\prime}}=7.62, \delta_{\mathrm{BB}^{\prime}}=8.29 \\
J_{\mathrm{AB}}=8.9, J_{\mathrm{BB}}=2.5 \\
J_{\mathrm{AB}}=0.4, J_{\mathrm{AA}}=2.5\end{array}$} & \multicolumn{2}{|c|}{-} & $7.35 \mathrm{~s}$ \\
\hline \multirow[t]{2}{*}{5} & \multirow{2}{*}{$\begin{array}{l}1.58 \mathrm{~s}, 3 \mathrm{H} \\
1.61 \mathrm{~s}, 3 \mathrm{H}\end{array}$} & \multirow{2}{*}{\multicolumn{2}{|c|}{$\begin{array}{l}2.80 \mathrm{~s}, 3 \mathrm{H} \\
2.85 \mathrm{~s}, 3 \mathrm{H} \\
\end{array}$}} & - & \multirow{2}{*}{\multicolumn{3}{|c|}{$\begin{array}{l}7.84,8.33, J \approx 9.0^{\mathrm{b}} \\
7.87,8.34, J \approx 9.0^{\mathrm{b}}\end{array}$}} & \multirow{2}{*}{\multicolumn{2}{|c|}{$\begin{array}{l}9.19 \mathrm{~s}, 1 \mathrm{H} \\
9.45 \mathrm{~s}, 1 \mathrm{H}\end{array}$}} & \multirow[t]{2}{*}{-} \\
\hline & & & & & & & & & & \\
\hline${ }^{13} \mathrm{C}$ & $\underline{\mathrm{CH}_{3}-\mathrm{C}}$ & $\underline{\mathrm{CH}_{3}-\mathrm{N}}$ & $\underline{\mathrm{C}}-\mathrm{CH}_{3}$ & $\underline{\mathrm{i}-\mathrm{C}-\mathrm{N}}$ & $\underline{\mathrm{C}}-\mathrm{NO}_{2}$ & $\mathrm{o}-\mathrm{C}$ & $\mathrm{m}-\mathrm{C}$ & $\underline{\mathrm{C}}=\mathrm{O}$ & & \\
\hline $1 b$ & 16.4 & 27.5 & 55.6 & 140.2 & 144.6 & 126.7 & 124.7 & 154.7 & & \\
\hline 2 & 22.1 & 23.7 & 83.2 & 139.9 & 144.6 & 126.5 & 123.6 & 153.2 & & \\
\hline 4 & 21.1 & 24.6 & 84.7 & 138.1 & 147.2 & 128.0 & 125.1 & 153.7 & 173. & $(\mathrm{C}=\mathrm{O})$ \\
\hline 5 & 17.5 & 24.8 & 91.3 & 139.8 & 145.5 & 124.2 & 127.2 & 154.4 & & \\
\hline & 17.7 & 24.8 & 91.7 & 139.9 & 145.5 & 124.3 & 127.4 & 154.5 & & \\
\hline
\end{tabular}

${ }^{\mathrm{a}}$ Revised data from ref. $4 .{ }^{\mathrm{b}}$ The AA'BB' patterns of $\mathbf{5}$ strongly overlap and $J$ 's obtained by daisy program are not reliable. 


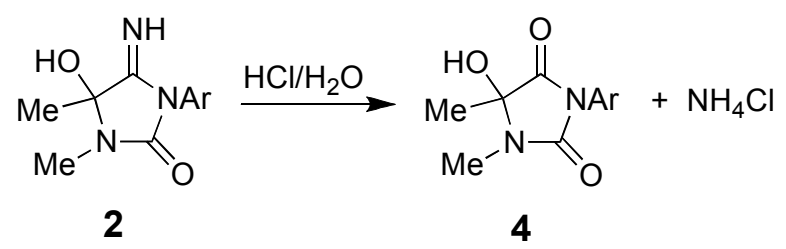

\section{Scheme 4}

In preparative scale experiments in ethanol or acetonitrile solution the first precipitate isolated in approximately 10\% yield was the peroxide 5. Its structure is based on the following facts. The molecular mass was confirmed by ES-MS. Compared to the 5-hydroxy-4-iminohydantoin 2 the ${ }^{1} \mathrm{H}$ NMR (Table 2) of 5 displays two sets of signals in a 1:1 ratio (within the error of integration of about $1-2 \%$ ); e.g., four different methyl groups. The ${ }^{13} \mathrm{C}$ NMR shows two different 5-C signals. The IR spectrum showed the presence of $\mathrm{NH}$, and no OH. The chemical shifts of protons bonded to heteroatoms are similar to those of $\mathrm{C}=\mathrm{NH}$ as observed for imines $\mathbf{1}^{4}$ and 2. Also the long range coupling of the methyl group (with the geminal $\mathrm{OH}$ group) as observed in $\mathbf{2}$ is absent in $\mathbf{5}$. Conclusive proof of the presence of two $\mathrm{NH}$ groups is obtained from the ${ }^{1} \mathrm{H},{ }^{15} \mathrm{~N}-\mathrm{HMBC}$ NMR spectrum of $\mathbf{5}$, part of which is given in Figure 2: it clearly shows that the two signals at $\delta 9.19$ and 9.45 for the imino protons correlate with ${ }^{15} \mathrm{~N}$ signals at $\delta 224-225$, and the corresponding cross peaks are doublets due to ${ }^{1} J_{\mathrm{NH}}=60 \mathrm{~Hz}$. Hence the peroxide structure 5 has been assigned to this product. When titrated with $\mathrm{KI}$ in $\mathrm{CHCl}_{3} / \mathrm{CH}_{3} \mathrm{CO}_{2} \mathrm{H} 1: 1$, peroxide 5 liberated $\mathrm{I}_{2}$; after a reaction time of $10 \mathrm{~min}$ at room temperature the liberated $\mathrm{I}_{2}$ titrated for approximately $90 \%$ equivalent (dialkyl peroxides notoriously react sluggishly with $\mathrm{KI})$. The IR spectrum shows the characteristic IR band for the $\mathrm{O}-\mathrm{O}-$ bond at $850 \mathrm{~cm}^{-1}$.

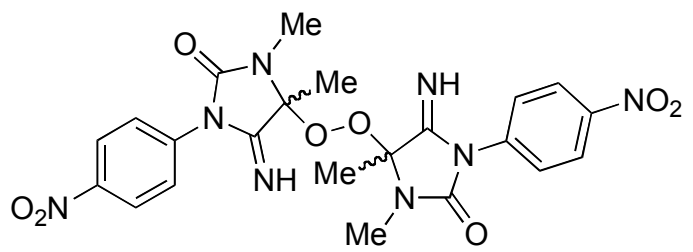




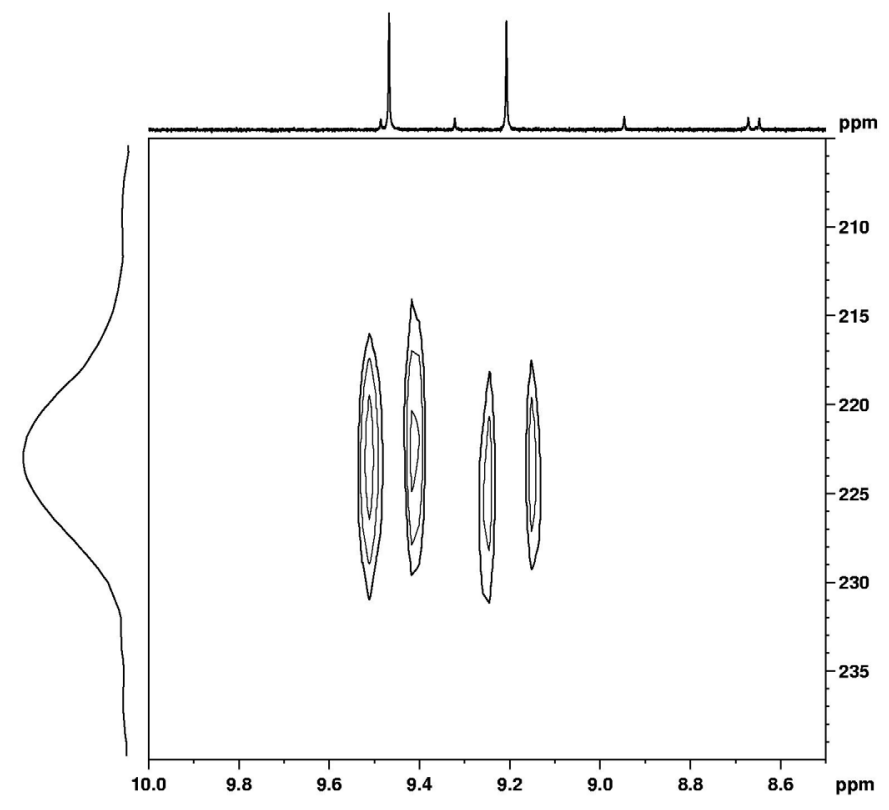

Figure 2. ${ }^{1} \mathrm{H},{ }^{15} \mathrm{~N}-\mathrm{HMBC}$ NMR spectrum of 5 measured in DMSO- $d_{6}$ on Bruker Avance II 600 $\mathrm{MHz}$ spectrometer using standard hmbcgpndqf pulse program. The number of scans were 1024, and 37 increments in F1 direction were accumulated.

As the peroxide structure is symmetrical, the four methyl signals in $\mathbf{5}$ instead of two must result from some kind of isomerism. There are two conceivable sources for isomerism: $E, Z-$ isomers around the $\mathrm{C}=\mathrm{NH}$ bonds or the two stereo centers at both $5-\mathrm{C}$. The former source can be discarded because we have shown ${ }^{4}$ that imines 1a,c exist predominantly as $E$-isomers $(E: Z \approx$ 10:1) in DMSO solution. Therefore, the 1:1 ratio of signal integrals should result from a mixture of $R^{*}, R^{*}$ and $R^{*}, S^{*}$ diastereomers. This composition could be due to practically zero energy difference in the respective (presumably early) transition states. However, in DMSO solution the two isomers 5 are formed in unequal amounts as indicated by the minor signals at $\delta 1.58$ and 1.61 (Figure 1); this goes along with unequal signal sets for the N-methyl groups of 5 in the same experiment: A rather inaccurate integral ratio of 3:2 was obtained. This suggests crystallization from ethanol or acetonitrile forms a 1:1 molecular complex of the two diastereomers. Attempts to separate the two isomers by multiple developments on t.l.c. (six times on a $20 \mathrm{~cm}$ strip of Merck DC-Alufolien Kieselgel $60 \mathrm{~F}_{254}$ using chloroform/acetone 4:1 as mobile phase; $R_{f}=0.16$ ) proved unsuccessful.

To check how important the energy difference between the two isomers can be, we computed the steric energies by means of the MM3 molecular mechanics force field.

Molecular mechanics modeling studies. The computational conformational analysis of the two diastereoisomers of 5 was carried out utilizing the MM3 force field. ${ }^{6-9}$ An effective dielectric constant 2.0 was used in the estimation of the electrostatic interactions. Starting geometries for 
the MM3 search of low-energy conformations were generated by combining the anticlinal and the antiperiplanar conformations for the rotations about the O-O-bond with the different combinations of values for the dihedral angles $\left(120.0^{\circ} \mathrm{step}\right)$ related to the rotational isomerism about the two 5-C-OO bonds. Some of the lowest-energy local minima thus obtained were further used as starting conformations for driver searches with $10.0^{\circ}$ steps. The block-diagonal Newton-Raphson procedure was used for minimizing the steric energies of the conformations. This minimization procedure does not always give convergent results for molecules containing aromatic rings. ${ }^{10}$ In order to avoid this problem, all conformations were further optimized with the full-matrix Newton-Raphson method. ${ }^{9}$ Identical conformations, which appeared as different conformations after the first stage of the minimization process, were eliminated in this way. This is a purely "technical" artefact originating from the block-diagonal Newton-Raphson minimization procedure in MM3 that may not always produce completely converged results for molecules containing aromatic rings, because they present cases with cooperative movements of the atoms on potential energy surface of small slope. ${ }^{10}$ The steric energies are summarized in Table 3 for the conformations of the two diastereomers.

The lowest energy conformation of the $R^{*} R^{*}$ isomer is calculated to be $0.5 \mathrm{kcal} / \mathrm{mol}$ higher than that of the $R^{*} S^{*}$ isomer. The ratio of $3 / 2$ for the two isomers in the reaction mixture corresponds to half this energy difference in the transition states leading to the two isomers.

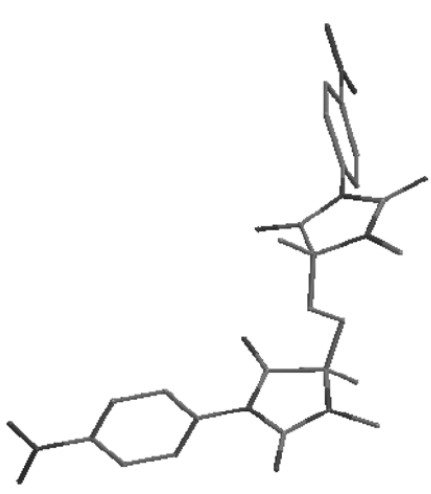

$\left(R^{*}, R^{*}\right)-5.1$

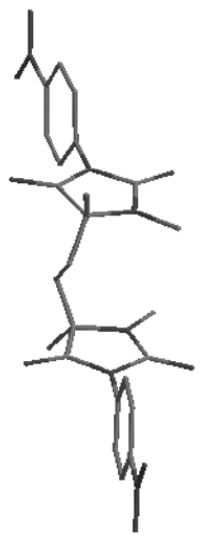

$\left(R^{*}, R^{*}\right)-5.5$

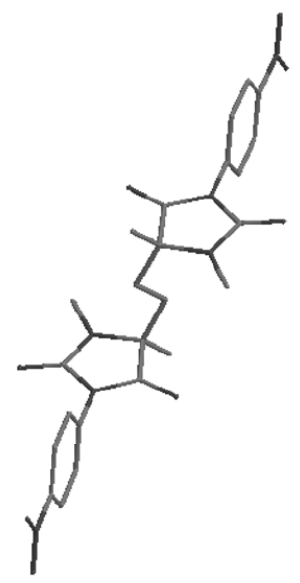

$\left(R^{*}, S^{*}\right)-5.1$

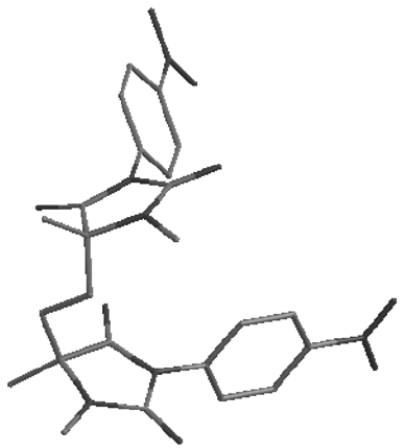

$\left(R^{*}, S^{*}\right)-5.5$

Figure 3. The optimized geometries of the lowest-energy antiperiplanar (5.1) and anticlinal (5.5) conformations of the diastereoisomers 5 (Table 3). 
Table 3. Computed MM3 conformational geometry and energy data of diastereoisomers $\mathbf{5}^{\mathrm{a}}$

\begin{tabular}{ccccc}
\hline & $\mathrm{C}-\mathrm{O}-\mathrm{O}-\mathrm{C}$ & $\mathrm{Me}-\mathrm{C}_{(\mathrm{R})}-\mathrm{O}-\mathrm{O}$ & $\mathrm{Me}-\mathrm{C}_{(\mathrm{R} / \mathrm{S})}-\mathrm{O}-\mathrm{O}$ & $\Delta E^{\mathrm{b}}$ \\
\hline \multicolumn{5}{c}{$\left(R^{*}, R^{*}\right)-\mathbf{5}$} \\
\hline 1 & 161.2 & -178.3 & -178.3 & $\mathbf{0 . 5}$ \\
2 & 166.3 & -175.2 & 65.7 & 1.5 \\
3 & 165.2 & 61.1 & 61.1 & 1.9 \\
4 & 175.7 & -60.3 & 179.8 & 2.8 \\
5 & 138.8 & 163.7 & 163.7 & $\mathbf{1 . 6}$ \\
6 & 149.9 & -52.1 & 70.3 & 2.4 \\
7 & 149.6 & 70.6 & -51.8 & 2.4 \\
8 & 138.6 & 112.2 & 84.4 & 2.9 \\
\hline \multicolumn{5}{c}{$\left(R^{*}, S^{*}\right)-5$} \\
1 & -176.1 & 174.8 & \\
\hline 1 & 178.5 & 178.0 & -66.4 & $\mathbf{1 . 2}$ \\
2 & -179.2 & -50.4 & 178.1 & 2.7 \\
3 & 160.2 & 63.3 & -61.4 & 2.3 \\
4 & 167.6 & 76.9 & 174.7 & $\mathbf{0 . 0}$ \\
5 & 146.7 & 72.9 & 84.7 & 1.1 \\
6 & 133.7 & 173.6 & 166.9 & 1.2 \\
7 & 156.4 & 64.0 & 62.8 & 2.3 \\
\hline & 154.4 & &
\end{tabular}

${ }^{\mathrm{a}}$ Units are degrees and $\mathrm{kcal} / \mathrm{mol}$. ${ }^{\mathrm{b}}$ The total steric energies of the lowest-energy conformers are $41.5 \mathrm{kcal} / \mathrm{mol}$ for $\left(R^{*}, R^{*}\right)-5$ and $41.0 \mathrm{kcal} / \mathrm{mol}$ for $\left(R^{*}, S^{*}\right)-5$.

\section{Discussion}

$\alpha$-Hydroxy derivatives are generally minor autoxidation products of imines; ${ }^{11}$ an exception has been observed ${ }^{12}$ with indandione anils involving a concurrent ring enlargement (Scheme 5).

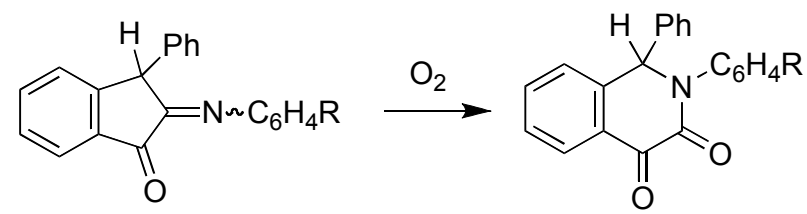

\section{Scheme 5}

The major products from autoxidation of imines or the related enamines with $\alpha$-hydrogen atoms are ketones accompanied by products due to breaking of $\mathrm{C}-\mathrm{C}$ bonds. ${ }^{11,13-15}$ In the absence of $\alpha$-hydrogen atoms, autoxidation of imines starts from an attack on $\mathrm{C}=\mathrm{N}$ initially yielding 
oxaziridines. $^{2,16}$ Recently, Törnqvist and coworkers ${ }^{17}$ found that 3-phenyl-1-methylthiohydantoins, the products from a modified Edman procedure for end group determination of proteins are degraded under basic conditions due to autoxidation. Their detailed study of 5-isopropylthiohydantoins revealed that in alcoholic media at high $\mathrm{pH}$ the major products are 5alkoxy together with 5-hydroxy derivatives; the latter type is observed in the present case. As thiohydantoins are rather strong $\mathrm{C}-\mathrm{H}$ acids the authors assume that autoxidation proceeds at the carbanion at 5-C. The same mechanism has been suggested before for the base-catalyzed autoxidation of carbonyl compounds with $\alpha$-hydrogen atoms, the crucial step being single electron attack of oxygen on the carbanion producing hydroperoxide as the product. ${ }^{18}$ Törnqvist and coworkers ${ }^{17}$ found no label in the alkoxy product upon oxidation with ${ }^{18} \mathrm{O}_{2}$ but $50 \%$ in the hydroxy product. This is taken as evidence that the alkoxy product is formed from a heterolytic cleavage of the peroxide giving peroxide anion and carbocation, the cation being seized by alcohol. The $50 \%$ label in the hydroxy product is strong proof for the involvement of homolytic cleavage of the peroxide.

We favor the latter pathway for the production of hydroxy imine $\mathbf{2}$ from imine $\mathbf{1 b}$ because hydroxy imine $\mathbf{2}$ is the major product of autoxidation even in ethanol. Reaction Scheme 6 is based on the preferred mechanism for enamine autoxidation ${ }^{18}$ involving single electron transfer of the tautomeric enamine $\mathbf{6}$ to molecular oxygen because of the unusually low oxidation potentials of enamines.

Peroxide 5 can be readily obtained from the coupling of peroxy radical 9 and radical 8 . Such a reaction is characteristic of stable radicals, ${ }^{19}$ which live long enough to encounter a peroxide radical; radical $\mathbf{8}$ is stabilized by neighboring double bond and a methyl group.

The observation that 4-imino-imidazolodin-2-one derivatives 1a (unsubstituted at 5-C) and 1c (5,5-dimethyl derivative) were found stable under conditions that caused oxidation of $\mathbf{1 b}$ is in line with Bolland's rule that a methyl group at the allylic position of olefins enhances the rate of autoxidation by a factor of about three. ${ }^{18}$ With the 5-methyl derivative $\mathbf{1 b}$ containing a similar $\left(\mathrm{CH}_{3}\right) \mathrm{CHC}=\mathrm{NH}$ moiety the effect of methyl substitution is apparently much more pronounced. An $\alpha$-methyl group in $\mathbf{1 b}$ is expected to enhance ${ }^{20}$ the population of the enamine in the tautomeric equilibrium (usually by one order of magnitude), thus explaining the ready susceptibility to autoxidation of the iminoimidazolidin-2-one with a tertiary $5-\mathrm{H}$. 


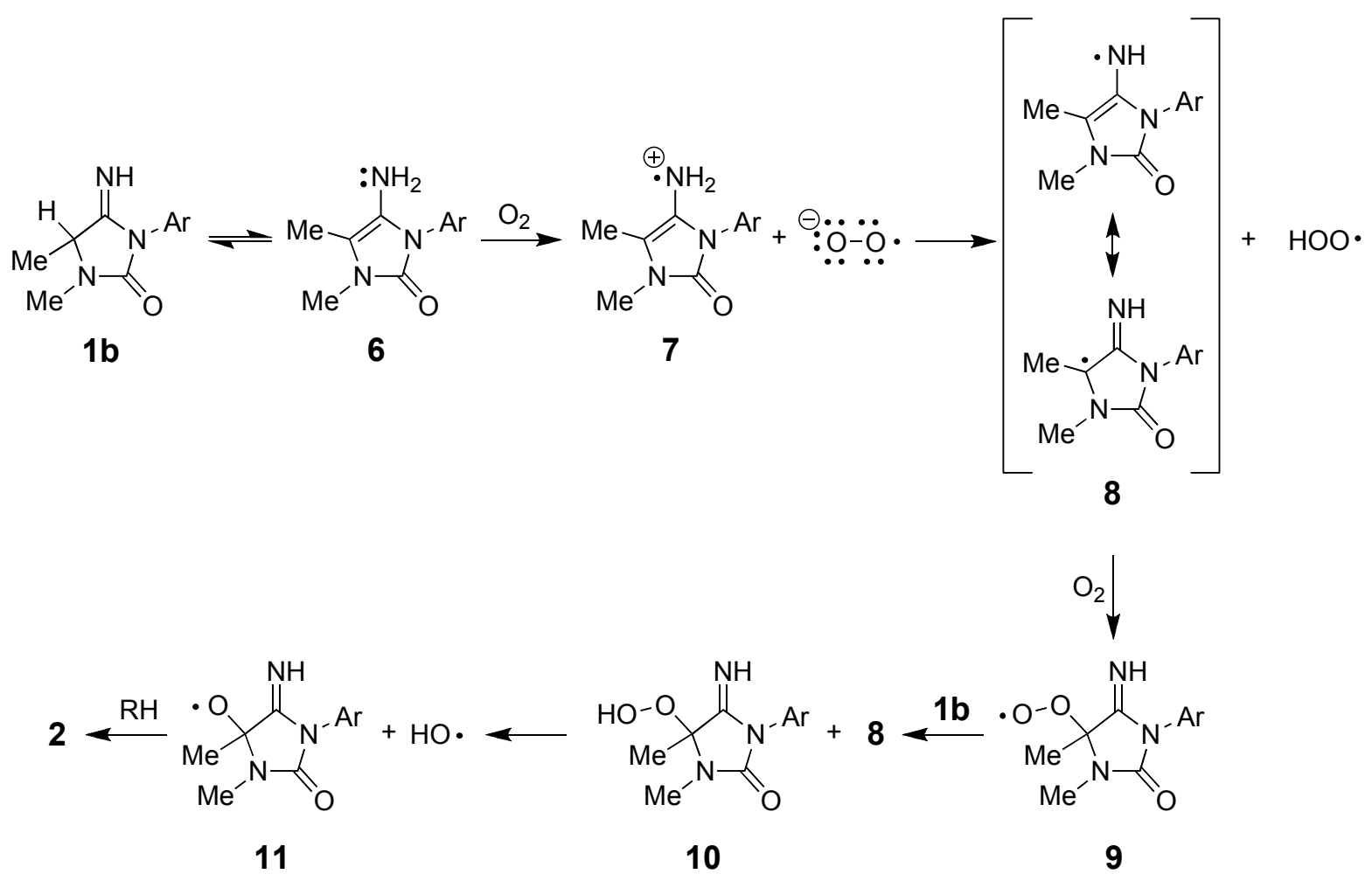

\section{Scheme 6}

\section{Conclusions}

In oxygen containing solutions 5-methyl-4-iminoimidazolidin-2-one $\mathbf{1 b}$ is readily oxidized to the 5-hydroxy derivative 2 . The reaction is chemoselective, and the facile hydrolysis of $\mathbf{2}$ in acid to 5-hydroxy-5-methylhydantoin 4 can provide a cheap and useful path to versatile synthons. As a minor product, the bis(imidazolidin-5-yl) peroxide 5 was isolated as a crystalline precipitate of $R^{*}, R^{*}$ and $R^{*}, S^{*}$ diastereomers, presumably as a 1:1 complex, though in the reaction mixture one of the isomers was formed in excess. MM3 computations indicate that the $R^{*}, S^{*}$ isomer is the more stable one. The search for potential minima emphasizes the need of full-matrix Newton-Raphson minimization in the case of cooperative movements of the atoms on potential energy surface of small slope (aromatic rings). ${ }^{10}$ The introduction of a single methyl group in position 5 of 4-iminohydantoins causes a drastic increase in the susceptibility to autoxidation.

\section{Experimental Section}

General Procedures. Melting points were measured in capillaries unless stated otherwise. IR spectra recorded with a Specord IR 75 or a Bruker IFS 113v instrument. 1D and 2D ${ }^{1} \mathrm{H}$ NMR 
spectra were recorded with a Bruker DRX-250 spectrometer, operating at $250.13 \mathrm{MHz}$, using a dual ${ }^{1} \mathrm{H} /{ }^{13} \mathrm{C}$ probe head in the digital filtering mode. The 1D spectra in $\mathrm{CDCl}_{3}$ and DMSO- $d_{6}$ were measured at $300 \mathrm{~K}$ with a digital frequency resolution of $0.06 \mathrm{~Hz}$ per point. The assignment of the ${ }^{1} \mathrm{H}$ and ${ }^{13} \mathrm{C}$ NMR spectra was accomplished by measurement of $2 \mathrm{D}$ homonuclear correlation (COSY), DEPT-135 and 2D inverse detected heteronuclear $(\mathrm{C}-\mathrm{H})$ correlations (HMQC and HMBC). The AA'BB' patterns were analyzed using daisy program included in TOPSPIN 2.0 software package.

MS spectra were measured utilizing a Q-Tof Ultima mass spectrometer (Micromass, Manchester, UK) equipped with a Z-spray type ESI source. Phosphoric acid was used for the positive ion mass calibration range of $\mathrm{m} / \mathrm{z}$ 100-2000. Data were acquired and processed using Masslynx version 4.0. The LockSpray interface facilitates acquisition of exact mass data on electrospray time-of-flight instrument using lock mass correction. Electrospray conditions: capillary voltage $3 \mathrm{kV}$; source temperature $80^{\circ} \mathrm{C}$; cone voltage $40 \mathrm{~V}$; source block temperature $160{ }^{\circ} \mathrm{C}$. The ESI nebulization and drying gas was nitrogen. All experiments were performed in the positive ion mode. The tof analyser geometry was in $\mathrm{V}$ optics mode. The sample and the reference compound (reserpine) were introduced orthogonally via a syringe pump operating at 5 $\mu \mathrm{l} / \mathrm{min}$.

Commercially available reagents and solvents were used. 4-Imino-1-methyl-3-(4-nitrophenyl)imidazolidin-2-one (1a) and 4-imino-3-(4-nitrophenyl)-1,5,5-trimethylimidazolidin-2one (1c) were prepared as described in ref. 4.

4-Imino-1,5-dimethyl-3-(4-nitrophenyl)imidazolidin-2-one (1b). N-(1-cyanoethyl)-N-methyl$\mathrm{N}^{\prime}$-(4-nitrophenyl)urea $\mathbf{2} \mathbf{b}^{4}(100 \mathrm{mg}, 0.40 \mathrm{mmol})$ was refluxed in dry ethanol $(10 \mathrm{~mL})$ for 15 min, and the solution was left in the refrigerator for 1-2 days. A small amount of crystalline side products was filtered off, and the filtrate was concentrated. Upon standing in a refrigerator for 13 days yellow crystals of $\mathbf{1 b}$ separated (77 mg, 77\%), pure according to ${ }^{1} \mathrm{H}$ NMR; mp 103-104 ${ }^{\circ} \mathrm{C}$ (lit. ${ }^{4} 103-104{ }^{\circ} \mathrm{C}$ ). ESI-tof HRMS: Calcd $\mathrm{C}_{11} \mathrm{H}_{12} \mathrm{~N}_{4} \mathrm{O}_{3}\left[\mathrm{M}+\mathrm{H}^{+}\right]$: 249.0987. Found: 249.0987. Solid cyanoalkylurea $\mathbf{3 b}$ left in a desiccator converted completely (NMR) into $\mathbf{1 b}$ over a period of 30 days.

Oxidation experiments were carried out in relatively dilute solutions of the substrate without additional introducing of air or oxygen unless specifically mentioned.

(a) In an NMR tube, $1 \mathbf{b}(2 \mathrm{mg})$ was dissolved in DMSO- $d_{6}$ or MeCN- $d_{3}(0.6 \mathrm{~mL})$ to give a 0.013 $\mathrm{M}$ solution. The tube was stoppered and kept at ambient temperature, and the conversion was followed by ${ }^{1} \mathrm{H}$ NMR. It can be calculated from solubility data in $\mathrm{Gmelin}^{21}$ that the oxygen dissolved and the amount contained in the free volume of the NMR tube exceeds the required stoichiometric amount for a 1:1 interaction. 


\section{Synthetic experiments}

Bis[5-hydroxy-4-imino-1,5-dimethyl-3-(4-nitrophenyl)-2-oxoimidazolidin-5-yl] peroxide (5). (1) 4-imino-1,5-dimethyl-3-(4-nitrophenyl)imidazolidin-2-one (1b) $(100 \mathrm{mg}, 0.427 \mathrm{mmol})$ was dissolved in $\mathrm{MeCN}(40 \mathrm{~mL})$ at ambient temperature, and air was passed through the solution for 4 days. The solution was cooled overnight in a refrigerator. Peroxide $\mathbf{5}$ separated as colorless crystals, which were filtered off and washed (10 mg, 9.4\%); mp of diastereomer mixture 228$230{ }^{\circ} \mathrm{C}$. NMR see Table 1. ES-MS Caled for $\mathrm{C}_{22} \mathrm{H}_{23} \mathrm{~N}_{8} \mathrm{O}_{8}\left[\mathrm{M}+\mathrm{H}^{+}\right]$: 527.16. Found: 527.31. Anal. Calcd for $\mathrm{C}_{22} \mathrm{H}_{23} \mathrm{~N}_{8} \mathrm{O}_{8}$ : C, 50.19; H, 4.18: N, 21.29. Found: C, 50.29; H, 4.21; N, 21.14. (2) Imine $1 \mathrm{~b}(42 \mathrm{mg}, 0.16 \mathrm{mmol})$ was refluxed in $\mathrm{EtOH}(4 \mathrm{~mL})$ for $15 \mathrm{~min}$. At this stage t.l.c. on Merck DC-Alufolien Kieselgel $60 \mathrm{~F}_{254}\left(\mathrm{CHCl}_{3} / \mathrm{EtOH}\right.$ 9:1) showed the presence of some unchanged starting material $\mathbf{1 b}\left(R_{f}=0.59\right)$, the hydroxy imine $\mathbf{2}\left(R_{f}=0.54\right)$, some peroxide $\mathbf{5}\left(R_{f}\right.$ $=0.69)$ and no hydrolysis product $4\left(R_{f}=0.64\right)$. Prolonged refluxing produced some 4 as well as other products. The peroxide 5 (4 mg, 9\%) crystallized after standing in the refrigerator for 1-2 days.

5-Hydroxy-4-imino-1,5-dimethyl-3-(4-nitrophenyl)imidazolidin-2-one (2). The filtrate after filtration of 5 (experiments in $\mathrm{MeCN}$ or in $\mathrm{EtOH}$ ) was concentrated on a rotatory evaporator. Upon standing in a refrigerator or freezer, yellow needles 2 separated $(52 \mathrm{mg}, 49 \%$ from the experiment in $\mathrm{MeCN} ; 20 \mathrm{mg}, 44 \%$ from the experiment in $\mathrm{EtOH}$ ), pure according to ${ }^{1} \mathrm{H}$ NMR; mp 134-136 ${ }^{\circ} \mathrm{C}(\mathrm{EtOH})$. ESI-tof HRMS: Calcd for $\mathrm{C}_{11} \mathrm{H}_{12} \mathrm{~N}_{4} \mathrm{O}_{4}\left[\mathrm{M}+\mathrm{H}^{+}\right]$: 265.0859. Found: 265.0940. Anal. Calcd for $\mathrm{C}_{11} \mathrm{H}_{12} \mathrm{~N}_{4} \mathrm{O}_{4}: \mathrm{C}, 50.00 ; \mathrm{H}, 4.55: \mathrm{N}, 21.21$. Found: $\mathrm{C}, 50.39 ; \mathrm{H}, 4.78 ; \mathrm{N}$, 20.95 .

5-Hydroxy-1,5-dimethyl-3-(4-nitrophenyl)imidazolidine-2,4-dione (4). Hydroxy imine 2 (20 $\mathrm{mg}, 0.076 \mathrm{mmol})$ was dissolved in $\mathrm{HCl}(0.1 \mathrm{M}, 1 \mathrm{~mL})$. Within $10-15 \mathrm{~min}$ a precipitate began to separate. The mixture was left in a refrigerator overnight. The colorless crystals $\mathbf{4}$ formed were filtered off, washed with water, and dried under vacuum (13 mg, 64,74\%); mp 185-187 ${ }^{\circ} \mathrm{C}$ (Kofler). Anal. Calcd for $\mathrm{C}_{11} \mathrm{H}_{11} \mathrm{~N}_{3} \mathrm{O}_{5}$ : C, 49.81; H, 4.18; N. 15.84. Found: C, 49.63; H, 3.70; N 16.25 .

\section{Acknowledgements}

We thank the National Science Foundation of Bulgaria (Grant X-1408) for financial support and Drs. Sabi Varbanov, Emma Marinova and Dimiter Tsankov of the Bulgarian Academy of Sciences for useful discussions and cooperation.

\section{References}

1. Herrerias, C. I.; Zhang, Li C.-J. Tetrahedron Lett. 2006, 47, 13.

2. Martiny, L.; Jørgensen, K. A. J. Chem. Soc., Perkin Trans. 1 1995, 699. 
3. Červinka, O. In The Chemistry of Enamines, Rappoport, Z., Ed., John Wiley, New York, 1994, 475.

4. Angelova, V. T.; Vassilev, N. G.; Koedjikov, A. H.; Pojarlieff, I. G. Bulg. Chem. Comm. 2003, 35, 122. Chem. Abstr. 2004, 141, 23150.

5. Meusel, M.; Gütschow, M. Org. Prep. Proced. Intern. 2004, 36, 393.

6. Allinger, N. L.; Yuh, Y. H.; Lii, J. H. J. Am. Chem. Soc. 1989, 111, 8551.

7. Lii, J. H.; Allinger, N. L. J. Am. Chem. Soc. 1989, 111, 8566.

8. Lii, J. H.; Allinger, N. L. J. Am. Chem. Soc. 1989, 111, 8576.

9. MM3(92), Technical Utility Corporation, 235 Glen Village Court, Powell, OH 43065.

10. Ivanov, P.M. Quantum Chemistry Program Exchange Bulletin 1986, 6, 6.

11. Hawkins, E. G. E. J. Chem. Soc. (C) 1971, 160.

12. (a) Pfeiffer, P.; de Waal, H. L. Liebigs Ann. Chem. 1935, 520, 185. (b) Pfeiffer, P.; Schmitz, E; Stöcker, H.; Kramer, H.; Reuter, G. Liebigs Ann. Chem. 1953, 581,149.

13. Blau, K. V.; Voerkel V. J. Prakt. Chem. 1989, 331, 285.

14. Pitacco, G.; Valentin, E. In: The Chemistry of Enamines, Rappoport, Z., Ed.; John Wiley, New York, 1994; pp 931.

15. Kulkarni, S. V.; In: The Chemistry of Enamines, Rappoport, Z., Ed., John Wiley, New York, 1994, 884.

16. Auret, B. J.; Boyd D. R.; Coulter, P. B. J. Chem. Soc., Chem. Commun. 1984, 463.

17. Rydberg, P.; Lüning, B.; Wachtmeister, C. A.; Erikson, L.; Tornqvist, M. Chem. Res. Toxicol. 2002, 15, 570.

18. Uri, N. In Autoxidation and Antioxidants, Lundberg, W. O., Ed., Interscience Publishers, New York, 1961, 1, 71. Gersmann, H. R.; Bickel, A.F. J. Chem. Soc. (B) 1971, 2230.

19. Swern, D. In: Comprehensive Organic Chemistry, Stooddart J. F., Ed., Pergamon Press, Oxford, 1979; Vol 1, Chapter 4.6.2.4.

20. (a) Keeffe, R. J.; Kresge, A. J. In The Chemistry of Enamines, Rappoport, Z., Ed., John Wiley, New York, 1994; 1058. (b) Wolfgang, W.; Meyer, H.-W. Liebigs Ann. Chem. 1974, 776. (c) Ahlrecht, H.; Kalas, R.-D. Liebigs Ann. Chem. 1979, 102.

21. Gmelins Handbuch der Anorganischen Chemie, 8 Auflage, Pietsch E.M.E., Ed., S.N. 3 Sauerstoff, Lieferung 3, Verlag Chemie, Frankfurt am Mein, 1958; pp 482. 